\section{Kinked inner tube of coaxial Bain circuit—need for corrugated inner tube}

\section{Rakesh Garg \\ Department of Anaesthesiolgy and Intensive Care, All India Institute of Medical Sciences, New Delhi, India}

To the editor: Bain circuit is a coaxial type of breathing circuit in which the inspiratory inner tubing is enclosed in a corrugated expiratory outer tubing. The corrugated tubing is preferred in view of its inherent advantage of flexibility and nonkinkability. In the Bain circuit the inner tube is noncorrugated and is liable to kink, as happened in one of our patients.

After the surgery was completed, the patient was supposed to be shifted to the intensive care unit with an endotracheal tube (ETT) in situ. The ETT was connected to a Bain circuit (Intersurgical, Wokingham, Berkshire, UK). After shifting the patient to a trolley, we observed that the reservoir bag was not getting filled adequately, although the fresh gas flow was $5 \mathrm{l} \cdot \mathrm{min}^{-1}$. Capnography showed an optimal waveform. No disconnection or obvious kink in the breathing system was observed. The machine pop-off valve went on and suddenly the Bain circuit got disconnected from the machine fresh gas flow outlet. On reattachment it again got disconnected with pressure. On close inspection we observed that the coaxial tubing of the Bain circuit was kinked by being compressed between the trolley and the operating table. The outer tubing appeared to be patent, but the inner tubing, as observed from the transparent outer tubing, was completely kinked. After straightening the tube, ventilation was possible.

On the first look in our patient, we probably ignored the possibility of kinking of the inner tube because of the presence of the nonkinkable corrugated outer tube of the Bain circuit. Later we checked for the kinkability of the coaxial tubing of the Bain circuit. Using a test lung bag, and connecting it to the Bain circuit, we deliberately kinked the tube from multiple sites in different tubes. We observed that the outer tube re- mained patent, probably because of the corrugations, but the inner tube kinked most of the time and the Bain circuit got disconnected from the fresh gas flow outlet.

There are no recommendations with regards to the type of tubing in a Bain circuit. Although the outer tubing is corrugated, the inner tubing is noncorrugated and is liable to kink. Also, the corrugated outer tubing may give false confidence in the nonkinkabilty of such a coaxial breathing circuit; the inner tube may get kinked, and this is not noticed.

In an earlier study, concerns related to the inner tube (disconnection of inner tubing from its seat at the machine end of the circuit), which were attributed to the flexion of the coaxial circuit were reported, suggesting that redesign of the circuit was needed [1]. A problem of inner-tube disconnection during lateral displacement of the coaxial tubing of a circle system, has also been reported, suggesting the need for redesigning of the coaxial circuit [2]. Kinking of an overlong inner tube, forming a double angulation ("Z" shape) within the outer tube, leading to total occlusion, has also been reported earlier [3].

We want to highlight to readers the possibility of the kinking of the inner tube of a Bain circuit. The feasibility and respiratory mechanics of the use of a corrugated inner tube in the Bain circuit need to be evaluated.

\section{References}

1. Ghai B, Makkar JK, Bhatia A. Hypercarbia and arrhythmias resulting from faulty bain circuit: a report of two cases. Anesth Analg. 2006;102:1899-913.

2. Jellish WS, Nolan T, Kleinman B. Hypercapnia related to a faulty adult co-axial breathing circuit. Anesth Analg. 2001;93:973-4.

3. Gooch C, Peutrell J. A faulty bain circuit. Anaesthesia. 2004;59: 618.

Address correspondence to: R. Garg, 58-E, Kavita Colony, Nangloi, Delhi-110041, India

Received: October 8, 2008 / Accepted: November 7, 2008 